Recepción: 15 / 04 / 2017

Ciencias Jurídicas

Aceptación: 01 / 05 / 2017

Artículo Científico

Publicación: 15 / 05 / 2017

\title{
La familia como factor criminógeno en la sociedad
}

The family as a criminological factor in society

\author{
A família como um fator criminógenas na sociedade
}

Ivonne M. Puga-Torres

ipuga09@hotmail.com

José E. Echeverria-Villafuerte " joseecheverria49@ hotmail.com

Correspondencia: ipuga09@hotmail.com

Doctora en Jurisprudencia y Ciencias Sociales; Magister en Ciencias Penales y Criminológicas; Especialista en Ciencias Penales y Criminológicas; Abogado de los Juzgados y Tribunales de la Republica; Licenciado en Ciencias Políticas y Sociales, Ecuador.

II. Magister en Ciencias Penales y Criminológicas; Especialista en Ciencias Penales y Criminológicas; Abogado de los Tribunales y Juzgados de la República del Ecuador; Ingeniero Comercial, Ecuador. 


\section{Resumen}

Dentro de la de la criminología, la familia es un factor muy importante en la consecución de infracciones, puesto que esta ciencia se preocupa de estudiar las causas que conllevan al cometimiento de un delito, por lo que dentro de los factores que determinan la causa de la criminalidad y delincuencia podemos determinar que la familia tiene un alto grado de responsabilidad en estos hechos. El ambiente natural y artificial constituye un estímulo constante al que el sujeto interactúa continuamente. Para el psicólogo Carl Rogers en sus teorías sobre la potencialidad innata de los seres humanos a la actualización óptima, considera que el ambiente puede fomentar o impedir la conducta humana, por lo que la familia es sin lugar a dudas el elemento más importante del medio donde vive el individuo, ella juega un papel esencial en el desarrollo de su personalidad así como en su comportamiento. Las funciones familiares son esenciales para la supervivencia de la sociedad y la conservación de su equilibrio. El individuo tiene necesidad de un cierto aprendizaje y de una adaptación social para su supervivencia, pudiéndose establecer que entre mayor sea la deficiencia de la familia como agente de socialización del niño, mayor es el riesgo de delincuencia y/o perturbaciones del comportamiento en el joven o adolescente. La familia juega un rol primordial y decisivo en el comportamiento del niño por ser primer modelo de socialización, donde se adquieren las conductas básicas, incluyendo variadas formas de represión y regulación conductual, pudiendo transformarse en un factor criminógeno en la sociedad. La ausencia de reglas, control o límites puede producir indecisión e inseguridad, y la ansiedad de éste proceso puede producir también en el niño agresividad e inadaptación; crece con ineptitud para tolerar cualquier frustración, de ahí la búsqueda ulterior de compensación y el refugio en la banda, alcanza un alto grado de desorganización social frente al mundo de valores considerados normales.

Palabras clave: Criminología; teorías de la criminalidad; familia; sociedad; factor criminógeno; endógenos; exógenos; adolescentes. 


\begin{abstract}
Within criminology, family is very important in achieving infringements factor, since this science is concerned with studying the causes that lead to the commission of a crime, so among the factors that determine the cause of crime and delinquency can determine that the family has a high degree of responsibility in these events. The natural and artificial environment is a constant stimulus to which the subject interacts continuously. For the psychologist Carl Rogers in his theories about the innate potential of human beings to the optimal update considers that the environment can promote or interfere with human behavior, so the family is undoubtedly the most important element of the environment where the individual lives, it plays an essential role in the development of their personality and their behavior. Family functions are essential for the survival of society and preservation of balance. The individual is in need of some learning and social adaptation for survival, being able to establish that the greater the deficiency of the family as an agent of socialization of the child, the greater the risk of crime and / or behavioral disturbances in young or adolescent. The family plays a central and decisive role in the child's behavior as being the first model of socialization, where basic behaviors, including various forms of repression and behavioral regulation and may become a criminogenic factor in society are acquired. The absence of rules, control or limits could result in indecision and insecurity, and anxiety of this process may also result in the child aggression and maladjustment; growing inability to tolerate any frustration, hence the search for further compensation and shelter in the band achieves a high degree of social disorganization to the world of values considered normal.
\end{abstract}

Key words: Criminology; theories of criminality; family; society; criminological factor; endogenous; exogenous; teenagers. 


\section{Resumo}

Dentro da criminologia, a família é muito importante na obtenção do fator de infração, uma vez que esta ciência está preocupada com o estudo das causas que levam à comissão de um crime, assim entre os fatores que determinam a causa do crime e a delinqüência pode determinar que a família tem um alto Grau de responsabilidade nesses eventos. O ambiente natural e artificial é um estímulo constante ao qual o sujeito interage continuamente. Para o psicólogo Carl Rogers em suas teorias sobre o potencial inato dos seres humanos para a atualização ideal considera que o ambiente pode promover ou interferir com o comportamento humano, de modo que a família é, sem dúvida, o elemento mais importante do ambiente onde o indivíduo vive, Um papel essencial no desenvolvimento da sua personalidade e do seu comportamento. As funções familiares são essenciais para a sobrevivência da sociedade e para a preservação do equilíbrio. O indivíduo precisa de alguma aprendizagem e adaptação social para sobreviver, podendo estabelecer que quanto maior a deficiência da família como agente de socialização da criança, maior o risco de delito e / ou distúrbios comportamentais em jovens ou adolescentes. A família desempenha um papel central e decisivo no comportamento da criança como sendo o primeiro modelo de socialização, onde os comportamentos básicos, incluindo várias formas de repressão e regulação comportamental e que podem se tornar um fator criminogênico na sociedade, são adquiridos. A ausência de regras, controle ou limites pode resultar em indecisão e insegurança, ea ansiedade deste processo também pode resultar na agressão e desajuste da criança; Crescente incapacidade de tolerar qualquer frustração, daí a busca por mais compensação e abrigo na banda atinge um alto grau de desorganização social para o mundo de valores considerados normais.

Palavras chave: Criminologia; teorias da criminalidade; família; sociedade; fator criminológico; endógeno; exógeno; adolescentes. 


\section{Introducción.}

La familia es la célula fundamental de la sociedad donde el niño debe aprender las normas y valores del medio en que vive; ella juega un rol decisivo en su desarrollo, al convertirse en su primer modelo producto de la interacción del grupo familiar. Se sostiene que como consecuencia de esa interacción, surgen a veces conductas delictivas o criminales y otras, que sin llegar a serlo, pueden llevar a sus miembros más débiles niños y adolescentes a manifestarlas dentro y fuera de su hogar. Esto comprueba que la familia puede constituirse en un factor criminógeno de la sociedad. (Steven $\mathrm{D}, 2004)$

Estudios sobre la materia, señalan que un $96 \%$ de menores con problemas tienen fallas en su grupo familiar: padres separados, núcleo desintegrado, padres desconocidos, alcohólicos o delincuentes, madres que trabajan, tensiones familiares provocadas por la pobreza, conflicto valorativo con el mundo circundante. Todos factores que provocan falta de modelos familiares y que impiden con ello ejemplaridad y como consecuencia, la falta de seguimiento. (Baquero Torres, 1999) (Dinitz, 1982)

Se une a lo anterior, la violencia psíquica o física de que pueden ser víctimas los menores, que los llevará sin duda, sino a cometer actos ilícitos, al menos a padecer serios trastornos en su conducta y en su vida de relación. (Chiossone, 1968)

Esta violencia que se ejerce contra la juventud y que obviamente, genera más violencia, se ve asegurada y difundida por los medios de comunicación masiva que la transmiten y la exaltan y producen más violencias en los jóvenes. No obstante, es la influencia familiar la que emerge decisiva en la conducta de los menores, imprimiendo una huella indeleble en su personalidad. (Cornell \& Benedek, 1987) 
La hipo nutrición, falta de educación, carencia de atención médica, explotación de los menores en tareas inapropiadas, pueden constituir factores que conduzcan al delito.

El presente estudio busca determinar el grado de responsabilidad que tiene la familia en el desarrollo de conductas criminales o delincuenciales dentro de los miembros de su grupo o de sus componentes.

\section{Materiales y métodos.}

El presente trabajo investigativo por su naturaleza jurídica es de carácter mixto, cuantitativo; y, cuantitativa porque para la investigación de campo se utilizó la estadística descriptiva, es decir encontramos datos cualitativos que fueron valorados, con la finalidad de profundizar la investigación sobre lo que es materia de este trabajo.

Consiste en el Estudio de la normativa, puesto que es necesario realizar un exhaustivo análisis sobre La Familia como Factor Criminógeno y las políticas, sus causas y consecuencias y las garantías de las personas que integran el vínculo familiar más aún los menores de edad.

El tipo de investigación que le correspondió al presente trabajo es la jurídica-descriptiva, porque aplicó el método analítico a un tema específico objeto de nuestro estudio, y también se enmarcó dentro de la investigación jurídica- crítica, porque nos permitió sugerir e impartir un criterio sobre el rol de la familia en el ámbito delincuencial principalmente en la etapa juvenil de las personas. Es decir, que la naturaleza jurídica del presente trabajo es de carácter descriptivo, crítico y explicativo.

Toda investigación se fundamenta en una base bibliográfica, complementándose con el estudio de campo, por medio del contacto directo con la realidad social, es decir con el universo 
objeto de estudio: Entrevista a personas conocedoras de la Criminología, para obtener información verídica, de acuerdo con los objetivos planteados. Por tanto el presente estudio es descriptivo, porque buscó encontrar las causas y consecuencias de esta modalidad delictual, y la emisión de un criterio respecto al tema de estudio, porque estuvo dirigida a determinar como es y cómo está la situación de las variables de la investigación.

\section{Descripción de la investigación de campo}

En la descripción de la investigación se tiene que determinar nuestro universo o población, luego seleccionar el tamaño de la muestra, mediante un método estadístico, lo que permitió realizar un trabajo investigativo veraz.

Procedimientos de la investigación

Toda vez que fue seleccionado el presente tema de investigación, procedí a la revisión bibliográfica sobre la Familia como factor criminógeno en donde se destacan muchos autores, así como la ayuda de las páginas de internet.

Con la información obtenida, procedí a realizar un análisis de la documentación obtenida para realizar la crítica referente al tema objeto de estudio.

Posteriormente realicé entrevistas a expertos conocedores de la materia quienes pudieron aportar sus criterios referentes al presente tema de investigación, los mismos que sirvieron para la realización de los datos estadísticos. 
El desarrollo de esta investigación se realizó en un proceso de análisis (conocimiento científico) sobre la Familia como factor criminógeno. El proceso metodológico se cumplió en las siguientes fases:
a) Estudio conceptual;
b) Construcción del marco de referencia.
c) Delimitación del objeto
d) Metodología del trabajo
e) Propuesta de intervención, convalidación y conclusiones.

La ejecución de esta etapa crítica se utilizó la investigación interactiva, puesto que se procede a consultar a juristas reconocidos en materia de Criminología, quienes a través de su criterio, no comparten la postura adoptada respecto a que la criminalidad tiene sus orígenes en la familia.

Técnicas e instrumentos de recolección de la información

Para la recolección de datos hemos visitado algunas bibliotecas con el fin de obtener información trascendental de la Criminología y a familia, estudiándolo con un enfoque social, legal y constitucional, así como la utilización de herramientas tecnológicas, para conocer los instrumentos internacionales y la legislación comparada.

\section{Resultados.}

Título No. 1 Considera usted que la familia es uno de los principales factores Criminógenos de la Sociedad. 
Ivonne M. Puga-Torres; José E. Echeverria-Villafuerte

\begin{tabular}{|c|c|c|}
\hline INDICADORES & SI & NO \\
\hline PROFESIONALES DEL & & \\
DERECHO & 8 & $\mathbf{2}$ \\
\hline JUECES & 6 & $\mathbf{0}$ \\
\hline FISCALES & 7 & $\mathbf{0}$ \\
\hline TOTAL & $\mathbf{2 1}$ & $\mathbf{2}$ \\
\hline
\end{tabular}

\section{Interpretación de Resultados}

Se evidencia que la mayoría de los entrevistados, que son personas conocedoras del derecho y la jurisprudencia, conocen coinciden en que el vínculo familiar tiene mucho que ver con la criminalidad, por lo que poseen vastos conocimientos al respecto de este tema.

Título No. 2 Considera usted que el problema familia y delincuencia solo son consecuencias afectivas.

\begin{tabular}{|c|c|c|}
\hline INDICADORES & SI & NO \\
\hline PROFESIONALES DEL & & \\
DERECHO & 1 & $\mathbf{9}$ \\
\hline JUECES & 4 & $\mathbf{2}$ \\
\hline FISCALES & 1 & $\mathbf{6}$ \\
\hline TOTAL & $\mathbf{6}$ & $\mathbf{1 7}$ \\
\hline
\end{tabular}

Interpretación de Resultados

Se evidencia que la mayoría de los entrevistados, coinciden en que más alla de la parte afectiva, existen otros elementos dentro de la familia que son altos factores de la criminalidad juvenil.

Título No. 3 Considera que actualmente se establecen buenos mecanismos para que se prevenga la delincuencia en las familias. 


\begin{tabular}{|c|c|c|}
\hline INDICADORES & SI & NO \\
\hline $\begin{array}{c}\text { PROFESIONALES DEL } \\
\text { DERECHO }\end{array}$ & 0 & $\mathbf{1 0}$ \\
\hline JUECES & 0 & $\mathbf{6}$ \\
\hline FISCALES & 0 & $\mathbf{7}$ \\
\hline TOTAL & $\mathbf{0}$ & $\mathbf{2 3}$ \\
\hline
\end{tabular}

\section{Interpretación de Resultados}

El 100\% de los entrevistados, están totalmente de acuerdo de que no existen elementos que permitan la prevención de la criminalidad en las familias, por lo cual debe el estado como política pública trabajar en este aspecto.

Título No. 4.- Considera que las zonas de mayor índice delictual son las urbano marginales y deben de ser consideradas de atención prioritaria.

\begin{tabular}{|c|c|c|}
\hline INDICADORES & SI & NO \\
\hline PROFESIONALES DEL & & \\
DERECHO & 2 & $\mathbf{8}$ \\
\hline JUECES & 5 & $\mathbf{1}$ \\
\hline FISCALES & 5 & $\mathbf{2}$ \\
\hline TOTAL & $\mathbf{1 2}$ & $\mathbf{1 1}$ \\
\hline
\end{tabular}

Interpretación de Resultados

Se evidencia que existen criterios divididos respecto de este tema, sin embargo consideran que la prevención delictual debe de realizarse mediante política estatal para las familias, y de esta manera se disminuirá la delincuencia desde temprana edad.

Título No. 5 Criterio, sobre la necesidad de implementación de medidas preventivas de la delincuencia en la familia como pilar fundamental de la sociedad 
Ivonne M. Puga-Torres; José E. Echeverria-Villafuerte

\begin{tabular}{|c|c|c|}
\hline INDICADORES & SI & NO \\
\hline PROFESIONALES DEL & & \\
DERECHO & 8 & $\mathbf{2}$ \\
\hline JUECES & 4 & $\mathbf{2}$ \\
\hline FISCALES & 5 & $\mathbf{2}$ \\
\hline TOTAL & $\mathbf{1 7}$ & $\mathbf{6}$ \\
\hline
\end{tabular}

\section{Interpretación de Resultados}

Se evidencia que la mayoría de los entrevistados, coinciden en que debe existir una serie de campañas como políticas de estado para la prevención delincuencial que inicie en los hogares y luego continúe en los establecimientos educacionales.

Título No. 6.- Con el endurecimiento de las penas se ha logrado la reducción de la criminalidad principalmente en los jóvenes.

\begin{tabular}{|c|c|c|}
\hline INDICADORES & SI & NO \\
\hline PROFESIONALES DEL & & \\
DERECHO & 3 & $\mathbf{7}$ \\
\hline JUECES & 4 & $\mathbf{2}$ \\
\hline FISCALES & 3 & $\mathbf{4}$ \\
\hline TOTAL & $\mathbf{1 0}$ & $\mathbf{1 3}$ \\
\hline
\end{tabular}

Interpretación de Resultados

Se evidencia que la mayoría de los entrevistados, que son personas conocedoras del derecho coinciden en que el endurecimiento de las penas no ha evitado la disminución de los delitos, puesto que se debe a un fenómeno social y sus causas tienen inicios en la familia, por ello se debe trabajar con las familias.

\section{Conclusiones.}


La familia representa el "núcleo de socialización” más importante para el niño, para lo cual se requiere que actúe de manera integrada, cumpliendo sus funciones de reproducción, protección y socialización. La calidad de esta última se encuentra estrechamente relacionada con las conductas delictivas desplegadas por el adolescente.

Una familia inestable o desorganizada puede favorecer del desarrollo de tendencias antisociales persistentes. Al desintegrarse la familia, también se desintegra la persona; entonces es ahí donde el individuo no le encuentra sentido a su vida, entonces se dedican a deteriorarse ellos mismos o a sus semejantes, ya sea robándoles, hiriéndolos o como se ha dado en otras situaciones, matando a familiares, incluso a sus propios padres. La ausencia física o psicológica del padre es un fuerte predictor de criminalidad, especialmente en el varón. No obstante, nos preguntamos si factores tales como la excesiva competitividad, la falta de oportunidades, la necesidad de que niños y jóvenes se incorporen tempranamente al mercado de trabajo y la transformación de los roles tradicionales de género ¿No hacen que el sistema sea tanto o más violento que las agresiones individuales de los jóvenes?.

Todo ello hace surgir la desconfianza y la intolerancia por la falta de certezas, restringiendo la socialización a los círculos más íntimos, mientras los espacios públicos se transforman en lo “anónimo y amenazador", estigmatizando la pobreza y la adolescencia y determinando su aislamiento por exclusión social.

De lo expresado se desprende que también la readaptación del delincuente se ve obstaculizada por la misma sociedad, que no favorece a la integración del ex convicto a ésta, 
privándolo de empleos que permitan poder tener una vida honrada, lo que lo lleva a reincidir en la delincuencia, como una forma de sobrevivencia.

Así, los "muros de contención” (cárceles, hospitales, instituciones), por un lado, protegen a la sociedad de los "inadaptados", pero también sirven para depositar y proyectar la angustia social ante una realidad cruel e implacable, quedando aquella "contenida" por el cemento La violencia y la delincuencia juvenil no son responsabilidad de personas individuales, se presentan en un contexto de múltiples variables, en una sociedad en donde la inestabilidad, la confusión y la desorganización afectan desproporcionadamente el funcionamiento de las familias, las que consciente o inconscientemente, exponen a sus hijos al peligro y a la desviación.

Las políticas implementadas hasta la actualidad, son, en general de carácter secundario o terciario, siendo necesaria la puesta en marcha de programas de prevención dirigidos a grupos de riesgo no específicos (conflictos familiares, fracaso escolar, consumo de drogas, interacción inadecuada con grupo de pares). No debemos limitarnos a la confección de un legajo, sino apuntar a un tratamiento integral, involucrando al grupo familiar y comprometiendo a las redes sociales del individuo.

\section{Bibliografía.}

Baquero Torres, M. (1999). De la atención institucionalizada a la integración social de la niñez infractora privada de la libertad. Derecho Penal y Criminología, 21(67).

Chiossone, T. (1968). Trastornos de la conducta juvenil. Venezuela: Universidad Central de Venezuela.

Cornell, D., \& Benedek, D. (1987). Características de los adolescentes acusados de homicidios. Ciencias del Comportamiento y Derecho.

Dinitz, S. (1982). Cómo impedir la criminalidad y la delincuencia juvenil. Revista Internacional de Criminología y Policía Técnica, 35(2).

Steven D, L. (2004). Entendiendo por qué se Redujo la Criminalidad en la Década de 1990: Cuatro Factores que lo Explican y Seis que No. Revista Ius et Praxis, 10(2), 97 - 135. 